\title{
Catecholamine-Induced Cardiomyopathy in Pheochromocytoma: How to Manage a Rare Complication in a Rare Disease?
}

Authors

Jenn Rachelle U. Santos ${ }^{1,2}$, Alessandra Brofferio ${ }^{3}$, Bruna Viana ${ }^{1}$, Karel Pacak ${ }^{1}$

Affiliations

1 Section on Medical Neuroendocrinology, Eunice Kennedy Shriver National Institute of Child Health and Human Development, Bethesda, MD, USA

2 University of Santo Tomas Hospital, España Boulevard, Manila, Philippines

3 Cardiovascular Branch, National Heart Lung and Blood Institute, Bethesda, MD, USA

Key words

cardiomyopathy, pheochromocytoma, paraganglioma, catecholamine

received 26.07.2017

accepted 31.07.2018

Bibliography

DOI https://doi.org/10.1055/a-0669-9556

Published online: 18.9.2018

Horm Metab Res 2019; 51: 458-469

(c) Georg Thieme Verlag KG Stuttgart · New York ISSN 0018-5043

Correspondence

Karel Pacak, MD, PhD, DSc, FACE

Senior Investigator

Chief, Section on Medical Neuroendocrinology,

NICHD, NIH

Building 10

CRC

Room 1E-3140

10 Center Drive MSC-1109

Bethesda

20892-1109 Maryland

USA

Tel.: + 1/301/402 4594, Fax: +1/301/402 4712

karel@mail.nih.gov

\section{ABSTRACT}

Pheochromocytomas and paragangliomas (PHEOs) are rare neuroendocrine tumors. Clinical manifestations include different cardiovascular signs and symptoms, which are related to excessive secretion of catecholamines. Catecholamine-induced cardiomyopathy in PHEO (CICMPP) is a rare but dreaded complication of PHEO. Once patient is diagnosed with this condition, the prognosis is worse and a surgical risk is much higher than expected. This article focuses on how catecholamines affect the heart and the pathophysiologic mechanism of CICMPP. The cardiovascular responses to catecholamine depend mostly on which catecholamine is released as well as the amount of catecholamine that is released. The acute release of norepinephrine and epinephrine from PHEO increases heart rate, systemic vascular resistance, myocardial contractility, and reduces venous compliance. The excessive adrenergic stimulation by catecholamine results in severe vasoconstriction and coronary vasospasm, myocardial ischemia, and subsequently damage, and necrosis. Chronically elevated catecholamine levels lead to significant desensitization of cardiac $\beta$-adrenoceptors. The increased levels of the enzyme $\beta$-adrenoceptors kinase ( $\beta A R K)$ in the heart seems to mediate these biochemical and physiological changes that are consistently correlated with attenuated responsiveness to catecholamine stimulation. Through these mechanisms different types of cardiomyopathy (CMP) can be formed. This review discusses extensively the 3 types of cardiomyopathies that can be present in a $\mathrm{PHEO}$ patient. It also provides the clinical presentation and diagnostic and therapeutic algorithm in managing patients with CICMPP.

\section{Introduction}

Pheochromocytomas (PHEOs) are mostly benign neuroendocrine tumors arising from chromaffin cells within the adrenal medulla, or anywhere in the plexus of sympathetic nerves for which they are called paragangliomas or extra-adrenal PHEOs [1]. In this manu- script, we use PHEO to cover both pheochromocytoma and paraganglioma. PHEOs are rare with an annual incidence of 3-8 cases per 1 million per year in the general population [2]. Clinical manifestations of these tumors include hypertension, tachyarrhythmia, headache, excessive sweating, tremulousness, chest pain, consti- 
pation, and several other symptoms and signs. The signs and symptoms are due to oversecretion of catecholamines [3]. Hypertension, that is the most common sign is present in $95 \%$ of patients with PHEO [4-6]. Severe cardiovascular complications are associated with hypertensive crisis due to sudden and profound catecholamine excess [5]. Acute or chronic hypertension can lead to myocardial hypoxia, which could lead to acute (ischemic, takotsubo) or chronic (hypertrophic, dilated) cardiomyopathy (CMP) [7-11].

Catecholamine-induced cardiomyopathy in PHEO (CICMPP) is a comparatively rare but very difficult to manage complication of PHEO. Retrospective studies reported prevalence of CICMPP at $8-11 \%$ of patients with PHEO $[12,13]$. CMP as an initial presentation of PHEO patients is, however, uncommon [13]. but it is still imperative to rule out PHEO as one of the causes of heart failure associated with profuse sweating, hypertension, pallor, and anxiety because management of such a patient would be different. It is also important to recognize CICMPP in patients before any surgery to reduce morbidity and mortality, especially due to catecholamine excess if anesthetics are given or any surgical procedure is performed [14].

Due to paucity of cases, there is still no specific therapeutic approach regarding the management of CICMPP. Management strategies are available, but they are based on retrospective studies and case reports. Thus, based on our experience with these patients and review of literature, this report outlines recommendations related to therapeutic approaches of CICMPP.

\section{How Catecholamines Affect the Heart?}

Catecholamines (dopamine, norepinephrine, and epinephrine) represent a group of neurotransmitters and hormones responsible for regulations of different physiologic processes and contribute to the pathogenesis of neurological, psychiatric, endocrine, and cardiovascular diseases [15]. They are synthesized in the brain, sympathetic nerves, and adrenal medulla [16]. They function both as hormones and neurotransmitters, which are essential in the different processes involved in cardiovascular system function. The postganglionic endings of sympathetic nervous system predominantly secrete norepinephrine, which bears a resemblance to epinephrine; hence sympathetic postganglionic fibers are usually called adrenergic fibers. The $\alpha$ - and $\beta-G$ proteins-coupled adrenoceptors mediate the pharmacological actions and cell responses to catecholamines [17].

In the heart, $\beta_{1}$-adrenoceptors are present in the sinoatrial node, atrioventricular node, and atrial and ventricular cardiomyocytes. $\beta_{2}$-Adrenoceptors are also found in the heart, vascular, uterine, and airway smooth muscle, and are responsible for the relaxation activity of this muscles. In myocardium, the activation of $\mathrm{G}_{\mathrm{s}}$-adenylyl cyclase-cAMP-protein kinase A (PKA) through the $\beta$-adrenoceptors leads to an increase in mitochondrial and cytosolic calcium, which increases contractility, heart rate, intracardiac pressure $\left(\beta_{1}\right)$, while the activation of $G_{i}$ proteins through $\beta_{2}$ adrenoceptors inhibit the production of cAMP by adenylyl cyclase causing myocardial relaxation [17]. Like the $\beta$-adrenoceptors, the $\alpha$-adrenoceptor has two subtypes, the $\alpha_{1}$ - and $\alpha_{2}$-adrenoceptors. $\alpha_{1}$-Adrenoceptors are further subdivided into three subtypes, the $\alpha_{1 \mathrm{~A}}, \alpha_{1 \mathrm{~B}}$, and $\alpha_{1 \mathrm{D}}$. The $\alpha_{1 \mathrm{~A}}$-adrenoceptor is the most abundant $\alpha_{1}$-adrenoceptor subtype in the heart [18]. $\alpha_{1}$-Adrenoceptors are mainly found in vascular smooth muscle and few expressions in cardiac muscles. They are located on the postsynaptic membrane of effector organs, while $\alpha_{2}$-adrenoceptors are found also in vascular smooth muscle but located on both presynaptic neurons and postsynaptic cells. The activation of $\alpha$-adrenoceptors produces vasoconstriction [17]. Signal transduction of $\alpha_{1}$-adrenoceptor leads to increased cardiac contractility in most conditions, but the net effect of different signaling responses is decreased force due to protein kinase $C$ (PKC) activation. Moreover, activation of $\alpha_{1}$-adrenoceptor results in formation of 1,4,5-inositoltriphosphate and diacyglycerol, and formation of 1,4,5-inositoltriphosphate results in the release of intracellular calcium, which is responsible in enhanced contractile force of the heart. Stimulation of $\alpha_{1 \mathrm{~A}}$-adrenoceptor also enhances the sensitivity of myofilaments to calcium, influx of transsarcolemmal calcium, and leads to intracellular alkalinization through $\mathrm{Na}^{+} / \mathrm{H}^{+}$exchanger. Chronic stimulation of $\alpha_{1}$-adrenoceptors may result in hypertrophic phenotype. On the other hand, $\alpha_{2}$-adrenoceptors have 3 different subtypes, the $\alpha_{2 A}, \alpha_{2 B}$, and $\alpha_{2 C}$. The $\alpha_{2}$-adrenoceptors have significant role inhibition of noradrenaline in the human heart, which becomes apparent under enhanced sympathetic activity. Norepinephrine and epinephrine exemplifies their positive ionotropic effects through stimulation of $\beta$-adrenoceptors, rather than $\alpha_{1}$-adrenoceptors [18].

Catecholamines at low concentration stimulate the heart by inducing $\mathrm{Ca}^{2+}$ movements, whereas excessive amounts of catecholamines promote cardiac dysfunction through intracellular $\mathrm{Ca}^{2+}$ overload in cardiomyocytes. Catecholamines at high concentration become oxidized to form aminolutins and produce oxygen free radicals. These oxidation products have been implicated to produce coronary spasm, arrhythmias, and cardiac dysfunction through sarcolemmal and sarcoplasmic reticulum $\mathrm{Ca}^{2+}$-handling abnormalities, mitochondrial energy production defects, and myocardial cell damage [19].

The overall cardiovascular response to norepinephrine through adrenoceptor activation, preferentially via $\alpha$-adrenoceptors, is increased in terms of cardiac output and systemic vascular resistance that leads to elevation in arterial blood pressure. Norepinephrine increases heart rate initially, but due to activation of baroreceptors and parasympathetically-mediated slowing of the heart rate, as a response to blood pressure elevation, there is a subsequent decrease in the heart rate [20].

Epinephrine, through the $\beta_{1}$-adrenoceptor, increases heart rate and contractility; its effects on $\alpha$-adrenoceptors produce vasoconstriction in most systemic arteries and veins. The total cardiovascular response of low to moderate concentration of epinephrine in the circulation is increased in cardiac output, which is redistributed to muscle and hepatic circulations with only a minimal change in mean arterial pressure. The minimal change in arterial pressure despite an increase in cardiac output, is brought about by the decrease in systemic vascular resistance secondary to activation of vascular $\beta_{2}$-adrenoceptors. At high plasma concentrations of epinephrine, the arterial pressure increases because of its binding to $\alpha$-adrenoceptors on blood vessels, which overdrives the vasodilatation mediated by the $\beta_{2}$-adrenoceptors [20].

At a low concentration, epinephrine preferentially attaches to high affinity $\beta_{2}$-adrenoceptors, causes vasodilatation, and a de- 
crease in systemic vascular resistance. As circulating epinephrine concentration increases, lower affinity $\alpha$-adrenoceptors start to attach epinephrine, which overdrives the $\beta_{2}$-adrenoceptor-mediated vasodilatation. At high concentrations of epinephrine, more $\alpha$-adrenoceptors are attached to epinephrine, thus producing a shift of balance to net vasoconstriction, which increases the systemic vascular resistance [20].

Cardiovascular responses to catecholamine depend mostly on which catecholamine is released as well as the amount of catecholamine that is released. Acute release of norepinephrine and epinephrine from PHEO increases heart rate, systemic vascular resistance, myocardial contractility, and reduces venous compliance [5]. However, excessive adrenergic stimulation by catecholamine results in severe vasoconstriction and coronary vasospasm, myocardial ischemia [21], and subsequently damage and necrosis [22, 23]. Chronically elevated catecholamine levels lead to significant desensitization of cardiac $\beta$-adrenoceptors [24]. The increased levels of the enzyme $\beta$-adrenoceptors kinase in the heart seems to mediate these biochemical and physiological changes that are consistently correlated with attenuated responsiveness to catecholamine stimulation [25]. The $\beta A R K$ is one of the $G$ protein-coupled receptor kinases that phosphorylates $\beta$-adrenoceptors after they have been excited, hence leading to their desensitization [26].

\section{Pathophysiology of CICMPP}

During physiologic conditions, catecholamine secretion is well controlled and regulated. However, in PHEO, catecholamines are often secreted in an uncontrolled and unpredictable manner [27]. The development of CMP is a chronic process that requires chronic sustained elevation of catecholamines as often seen in PHEO. More specifically, norepinephrine can augment myocardial oxygen demand, cell death and injury, attenuates cardiac performance, thus leading to systolic heart failure and dilated CMP [28]. The disproportion between myocardial oxygen supply and demand leads to subendocardial ischemia [29].

Some of the mechanisms involved in catecholamine-induced CMP include desensitization of $\beta_{1}$-adrenoceptors, intracellular calcium overload, oxidative stress, and mitochondrial dysfunction. The over excitation of $\beta_{1}$-adrenoceptors heightens the inotropic and chronotropic activities of the heart and is accompanied by secondary rise in myocardial oxygen demand, surpassing the oxygen delivery often producing hypoxic areas in the heart [30, 31]. The significant elevation in the myocardial cytosolic and mitochondrial calcium is the hallmark of sustained catecholamine exposure [22]. The excessive accumulation of calcium in the mitochondria initiates oxidative stress and mitochondrial permeability transition ultimately leading to apoptosis and necrosis ( $>$ Fig. 1) [31]. The oxidative stress brought about by prolonged exposure to high catecholamine levels initiated by increased mitochondrial calcium occurs via the following mechanisms: 1) during oxidative deamination of catecholamines, hydrogen peroxide is formed, and through catalysis, hydrogen peroxide may be transformed to a more reactive hydroxyl radical [30], 2) stimulation of $\alpha_{1}$-adrenoceptors by catecholamines activates nicotinamide adenine dinucleotide phosphate (NADPH) oxidase and consequently the production of superoxide anion radicals in heart muscle cells [32], and 3) toxic compounds called "aminochromes" are formed by auto-oxidation (low rate) of catecholamines. The process of auto-oxidation is significantly sped up by the presence of oxygen free radicals and by catalysis brought about by different enzymes such as xanthine oxidase, myeloperoxidase, and cytochrome oxidase.

The oxidation of catecholamines also produces cardiotoxicity [33]. Several studies elucidated the different cellular toxicity of ami-

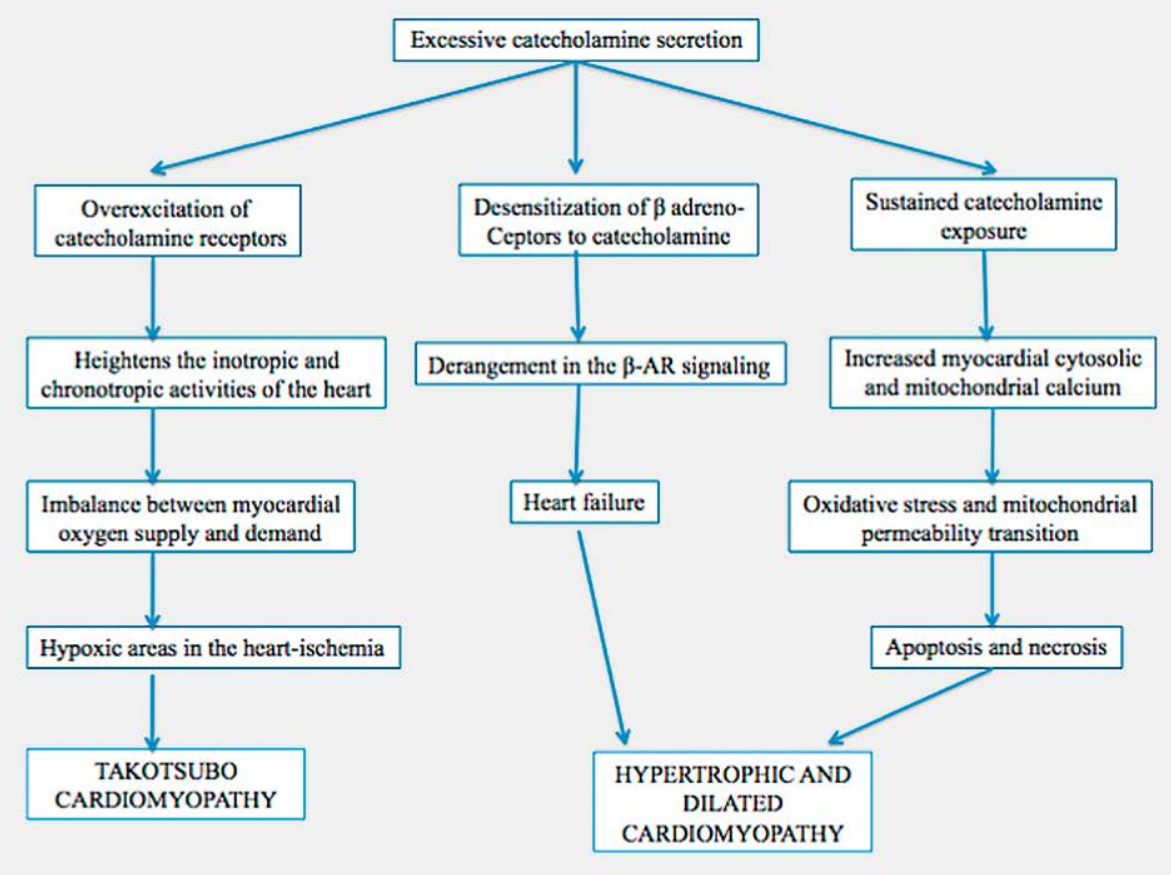

- Fig. 1 Pathophysiology of catecholamine-induced cardiomyopathy pheochromocytoma [21, 22, 29-31,43,44]. $\beta$-AR: Beta adrenoceptor. 
nochromes in the cardiac and nervous tissue [34, 35]. In the coronary vasculature, aminochromes employ their direct toxic effects by vasoconstriction. The adrenochrome, which is formed through oxidation of epinephrine by tyrosine [36], induced arrhythmias and sudden cardiac death in anesthetized rats [37]. The rate of reaction for epinephrine is significantly faster compared to norepinephrine, thus the reduction peak for adrenochrome is larger for epinephrine; it shifts the equilibrium potential favoring more production of epinephrine. Yates et al. assessed the effects of adrenochrome and other metabolites of epinephrine on the contractile activity of the rat's heart and study showed that those hearts perfused with adrenochrome showed histologic damages. During higher concentrations of adrenochrome and after $10 \mathrm{~min}$ of perfusion, there were alterations in the appearance of the mitochondria characterized by ultrastructural changes. This study concluded that adrenochromes were partly responsible for producing heart failure and necrosis following massive catecholamine injections in intact animals [38]. In the study done in rat by Taam et al., the authors determined the effects of adrenochrome on myocardial energy production by examining changes in the content of adenine nucleotide and mitochondrial oxidative phosphorylation activities of the heart. The adrenochrome-perfused rats' hearts displayed a striking decline in the contractile force within 5 min and this was coupled with rapid decreased in ATP/AMP ratio. At higher concentrations of adrenochrome, there was inhibition of the mitochondrial oxidative phosphorylation activities in the heart. This inhibitory effect strengthened the same mechanism involved in the presence of excessive mitochondrial calcium. The adrenochrome together with excessive calcium in the cardiac myocytes may weaken the process of energy production in mitochondria and this may decrease cardiac contractility [39]. Although there are lots of studies involving aminochromes, there is still no study involving measurement of aminochrome levels in patients diagnosed with PHEOs.

\section{Clinical Presentations of Different Types of CICMPP}

A suspicion of CICMPP should always be made whenever a PHEO patient presents with symptoms of heart failure, hypotension, and multisystem crisis in the absence of coronary and valvular heart disease or with no known definite etiology. There are 3 types of cardiomyopathies that can be present in a PHEO patient. Zhang et al. did an analysis on the association of PHEOs and CMP [40]. They included 163 cases of PHEO with CMP [63 dilated cardiomyopathy (DCM), 38 takotsubo cardiomyopathy (TCM), 30 inverted TCM, 10 hypertrophic cardiomyopathy (HCM), 8 myocarditis, and 14 were of unspecified type]. Hypertension was more prevalent in those with HCM (80\%) and DCM (83\%) than the classic TCM and inverted TCM, myocarditis and unspecified type of CMP [40]. Hypertension is common to PHEO and in itself can cause CMP [41]. Moreover, Fereirra et al. in their study found that previously diagnosed PHEO patients had a normal left ventricular mass index compared to their healthy control counterparts, and a lower left ventricular mass index compared to their hypertensive control counterparts and newly diagnosed patients preoperatively [42]. Palpitations, headache and diaphoresis were more prevalent in patients with
$\mathrm{HCM}$, while congestive heart failure at first presentation were common in those with DCM as compared to other subtypes [40].

Different types of CMP are formed by means of heart adaptation to catecholamine excess. Heart overstimulation by catecholamine leads to reversible $G_{s}$ to $G_{i}$ intracellular activation of $\beta_{2}$ receptors predominantly in the apex resulting to decreased contractility and hypokinesia, which automatically returns to $\mathrm{G}_{\mathrm{s}}$ signaling with reduced stimulation, characterized TCM. On the other hand, HCM and DCM involves sympathetic stimulation of cardiac muscles, which leads to adaptive mechanisms and resulted to $\beta$ adrenoceptors desensitization $[40,43]$. In spite of this compensatory mechanisms, chronic exposure to catecholamine results to interstitial fibrosis, cardiac muscles apoptosis, and reduced contractility due to structural changes leading to CMP as seen in HCM and DCM [44].

As to what type of cardiomyopathy in a patient with untreated PHEO will develop is still unknown, whether it is related to some certain biochemical phenotypes is still a question for researchers, but chronicity of exposure to catecholamine and means of adaptations of cardiac myocytes to catecholamine exposure are some of the factors $[40,43]$.

\section{Dilated cardiomyopathy (DCM)}

CICMPP is usually associated with characteristic features of DCM. Common features of DCM as seen by 2-dimensional (2-D) echocardiogram or cardiac MRI include enlarged left ventricle (LV), eccentric hypertrophy with global systolic dysfunction that is not attributable to ischemic or valvular heart disease. The echocardiogram may also show dilated left atrium, elevated end diastolic pressure, and upper normal range or modestly elevated pulmonary artery pressure [10, 45-49].

\section{Takotsubo cardiomyopathy (TCM)}

Takotsubo-like CMP presents often with acute chest pain, occasionally with symptoms of heart failure and most commonly with S-T segment changes mimicking acute coronary syndrome, accompanied with regional LV dysfunction and mildly abnormal cardiac biomarkers [9, 50-52]. It is an acute, reversible condition, which involves a stress- or neuroendocrine-mediated process with distinct echocardiographic findings of apical ballooning (contractile dysfunction most prominent at the apex) and hypercontractility at the base of the left ventricle. Some patients also present with reversed TCM characterized by wall motion abnormality of the basal portions of the left ventricle with compensatory hyperkinesia at the apex [53-55]. The coronary angiography shows no evidence of acute obstructive coronary artery disease (CAD). The dysfunction is attributed to catecholamine surge leading to regional microvascular dysfunction accompanied by intracellular calcium overload [56]. Wittstein et al. also suggested that it may also be related to catecholamine-induced reversible coronary vasoconstriction leading to myocardial ischemia [57].

Agarwal et al. performed the analysis of 38 patients with takotsubo cardiomyopathy in PHEO (TCM-PHEO) and compared it with a review, which examined primary takotsubo cardiomyopathy (TCM-p). They found that unlike in TCM-p, TCM-PHEO have less common antecedent stressors [58]. Occasionally, they would present with severe left ventricular dysfunction, akinetic segments at base and mid ventricle, and hyperkinetic apex (inverted/reversed 
TCM) $[52,59]$. Other studies suggested that variations in the anatomy of cardiac sympathetic nerves and distributions of adrenoceptors might have been the cause of differences in the segmental wall motion abnormality of the myocardium. Regardless of the presentation, whether classic or inverted/reversed, TCM-PHEO should be considered in patients diagnosed with acute coronary syndrome with unremarkable coronary angiogram results but with pronounced blood pressure variability [60].

\section{Hypertrophic cardiomyopathy (HCM)}

In patients with HCM, symptoms of heart failure may develop at any age, with limitation in functional capacity due to fatigue or exertional dyspnea. In advanced stages, they may be accompanied by orthopnea or paroxysmal nocturnal dyspnea. Patient may experience chest pain in the absence of atherosclerotic CAD, and this may result from structural microvasculature abnormalities. Patient may have syncope, near-syncope, or light-headedness due to arrhythmias or outflow tract obstruction. Palpitations are usually not uncommon and may be secondary to ventricular or supraventricular arrhythmias. Physical examination findings may be variable. A medium-pitch systolic ejection murmur is present at the lower left sternal border and apex, which changes in intensity depending on the magnitude of the subaortic gradient. Increased voltages secondary to left ventricular hypertrophy, ST-T changes, left atrial enlargement, deep and narrow $Q$ waves, and diminished $R$ waves in the lateral precordial leads are the most common electrocardiographic abnormalities [61]. Huddle et al. and Jacob et al. reported cases of PHEO associated with echocardiographic features simulating hypertrophic obstructive cardiomyopathy. Both patients have left ventricular posterior wall and inter-ventricular septal hypertrophies, with systolic anterior motion of the anterior mitral valve leaflet, elevated mean left ventricular outflow gradient with normal ejection fraction. Repeat echocardiography several months after resection of PHEO showed absence (decreased for Jacob et. al.) of systolic anterior motion of the anterior mitral valve leaflet with significantly decreased left ventricular outflow gradient and still with normal ejection fraction $[11,62]$. The hypertrophic changes are in part attributable to direct toxic effect of catecholamine in the myocardium. These echocardiographic features of obstructive hypertrophic cardiomyopathy frequently disappeared or improved after surgical resection of PHEO $[63,64]$ > Table 1 shows the echocardiographic findings of different types of catecholamine-induced cardiomyopathy.

\section{Associated Clinical Features, Diagnostic Tests and Imaging Features that Could be Present in all Three Types of CICMPP}

\section{Left ventricular dysfunction as a feature of CICMPP}

Fereirra et al. conducted a prospective study investigating the extent of cardiac involvement on PHEO patients using cardiac MRI. This study includes 125 subjects comprising of newly $(n=29)$ and previously $(n=31)$ diagnosed PHEO patients, age- and sex-matched healthy control subjects ( $n=51$ ), and subjects with essential hypertension ( $n=14)$. The cardiac MRI findings of each group of PHEO patients were compared with both age- and sex-matched healthy control subjects and hypertensive control subjects. The study revealed that newly diagnosed PHEO patients had lower mean left ventricular ejection fraction (LVEF) as compared to both control subjects. Postoperatively, follow up paired analysis showed an improvement on the average LVEF. There was mild global left ventricular dysfunction (LVEF $44 \%$ to $56 \%$ ) in $38 \%$ (11 out of 29 ) of patients, but in those available for follow up, returned to normal at 1 year post operatively. Impaired peak systolic circumferential strain and diastolic strain was seen at newly diagnosed patients during baseline interrogations as compared with both control subjects (both $\mathrm{p}<0.05$ ). During follow up paired analysis, these dysfunctions still remained [42].

Subjects with previously diagnosed and surgically removed PHEO had a normal mean LVEF, and higher than the newly diagnosed subjects. However, there was no difference when compared with both control subjects (both p value not significant). Despite the normal LVEF, these subjects had mildly impaired peak systolic circumferential strain compared to their healthy control counterparts, but there was no significant difference when compared to the hypertensive control subjects. With regards to their diastolic strain rate, previously diagnosed and surgically removed PHEO patients had significantly more impaired diastolic strain rate compared with both control subjects. This impairment was also seen post operatively in newly diagnosed patients during follow up [42].

In PHEO-induced CMP, ventricular function may be improved and returned to baseline post surgery, however, the abnormality with regards to peak systolic strain rate and diastolic strain rate persisted [40].

\section{Acute coronary syndrome-like presentation}

PHEO patients could also present with symptoms, laboratory and ECG findings suggestive of acute coronary syndrome. In some case studies, patients presented with symptoms of retrosternal pain ra-

- Table 1 Echocardiographic findings of different types of catecholamine-induced cardiomyopathy in pheochromocytoma.

Types of Cardiomyopathy and Echocardiographic Findings

Dilated

Dilatation of LV and possibly RV with no to minimal wall thickening (eccentric hypertrophy), with or without LV systolic dysfunction. LV global hypokinesia is commonly seen however SWMA may also be present [56]

\section{Takotsubo}

Classic-apical ballooning (contractile dysfunction most prominent at the apex) and basal hyperkinesia [56]. Reversed/inverted- akinetic segments at base and mid ventricle, and hyperkinetic apex. [52,59]

\section{Hypertrophic}

Typically normal or reduced dimensions of internal chamber, significant wall thickening (concentric hypertrophy), with or without systolic anterior motion of anterior mitral valve leaflet [61]

LV: Left ventricle; RV: Right ventricle; SWMA: Segmental wall motion abnormality. 
diating to both upper limbs, accompanied by palpitations. The ECG revealed ST depression in the anterior and inferior aspects, elevated troponin T, and echocardiogram showed severe hypokinesis of anterior septal, basal, inferior, and posterior segments with normal systolic function [48]. On the other hand, due to high levels of catecholamines, even without myocardial ischemia or infarction, patients can present with inverted T waves, hyperacute T waves, ST elevation, abnormal $R$ wave progression, and diffused low voltage [65].

In a study done by Schurmeyer et al. including 106 patients, endocrine and cardiologic findings in 106 patients with PHEO were assessed. It was found that $26 \%$ of patients had symptoms of CAD, $24 \%$ of patients had problems with contractility, $12 \%$ presented with possible myocardial infarction, $7 \%$ with acute left heart failure, and $6 \%$ with myocardial infarction [45]. However, several studies showed that coronary angiography usually revealed no evidence of significant obstructive CAD even if patients presented with clinical signs and symptoms of myocardial infarction, CAD, or heart failure [49, 66-69]. Coronary angiography is basically used to establish the presence and severity of obstructive CAD in a condition in which a diagnosis is not certain and CAD cannot be ruled out by non-invasive testing [70]. Unless patients have significant risk factors for CAD, objective evidence of acute myocardial infarction, and absolute indications for coronary angiography, coronary angiography is not cost effective in patients with PHEO, although this should still be proven in a randomized control study.

\section{Acute pulmonary edema}

PHEO patients could also present with symptoms and signs of pulmonary edema and/or hypertensive crisis, and rarely with refractory cardiogenic shock requiring mechanical circulatory support $[51,71]$. Acute onset of dyspnea due to pulmonary edema has been described as the initial presentation of PHEO [72,73]. Pulmonary edema is believed to be caused by decompensation in the setting of CMP and severely increased peripheral vascular resistance [72]. Moreover, patients rarely presented with non-cardiogenic pulmonary edema due to catecholamine-induced transient elevation in pulmonary capillary pressure, and permeability $[73,74]$ increased pulmonary neutrophil accumulation [73], increased hydrostatic pressure due to overfilling or constriction of the pulmonary veins even in the absence of overt left ventricular dysfunction.

\section{Myocarditis}

Chronic exposure to catecholamine leads to downregulation of $\beta$-adrenoceptors leading to suboptimal function of myofibers and decreased number of contracting units. The histologic changes that are usually observed include contraction band necrosis, neutrophil infiltration, and fibrosis. Myocarditis can be also caused by sudden excessive release of catecholamines, which produces diffused myocardial edema seen on $\mathrm{T} 2$ weighted images and focal midwall late gadolinium enhancement (LGE) on cardiac MRI [47]. Thus, patients with catecholamine-induced myocarditis usually present with heart failure symptoms such as easy fatigability, dypnea, paroxysmal nocturnal dyspnea, and bipedal edema. This may emulate several cardiac conditions, rendering difficulty in definitive diagnosis. Diagnostics tests like ECG, chest X-ray, and echocardiogram are inconclusive of myocarditis compared to cardiac MRI that can show myocardial changes specific for acute myocarditis.
Fereirra et al. found that there was an increase in the incidence of focal myocardial fibrosis in both newly diagnosed and previously diagnosed patients with PHEO. On cardiac MRI, 59\% of newly diagnosed $\mathrm{PHEO}$ patients exhibited a non-ischemic pattern (midwall, subepicardial, or patchy) scarring. Native $T_{1}$ mapping can be used to assess myocardial fibrosis in various cardiomyopathies [75, 76]. The study of Ferreira et al. also revealed that newly diagnosed PHEO patients had significantly higher average left ventricular myocardial $T_{1}$ values when compared with those of healthy and hypertensive control subjects (both $\mathrm{p}<0.05$ ). Newly diagnosed PHEO patients showed significantly larger areas of myocardial involvement compared to their controlled (healthy and hypertensive) counterparts. Moreover, during follow up paired analysis, the area of $\mathrm{T}_{1} \mathrm{ab}$ normality was significantly reduced, although it did not return to normal compared with healthy control subjects. Subjects with previously diagnosed, surgically treated PHEO with no evidence of active disease also exhibited significantly bigger areas of involvement of myocardium as detected by native $T_{1}$ mapping as compared with both control groups. This finding was similar to that observed in newly diagnosed patients during follow up post operatively [42].

\section{Arrhythmias}

In a review done by Lenders et al. it was found that around 50-70\% of patients with PHEO experienced palpitations [77]. Cardiac arrhythmias may be present in $20 \%$ of patients with $\mathrm{PHEO}$ and include sinus tachycardia, sick sinus syndrome, supraventricular tachycardia, and ventricular tachycardia [49-55, 57-78]. In a study by Schumayer et al., ECG on admission was recorded in $\mathrm{PHEO}$ patients and it was concluded that there were no typical ECG abnormalities that would characterize excessive catecholamine secretion [45].

Some ECG findings that may be found in catecholamine-secreting $\mathrm{PHEO}$ patients include right axis deviation, generalized low voltage [79], ventricular hypertrophy [80], abnormal R wave progression, abnormally peaked $P$ waves, low amplitude or inverted T waves, elevation of ST segment, T wave changes, prolonged corrected QT interval, sick sinus syndrome, supraventricular and ventricular tachycardia, torsades de pointe, and ventricular fibrillation [65, 81-84].

$\mathrm{PHEO}$ is a rare cause of fatal arrhythmia like ventricular tachycardia and torsades de pointes $[85,86]$. There is still no exact data regarding the incidence of fatal arrhythmias in patients with $\mathrm{PHEO}$. The prolonged excessive catecholamine secretion from PHEO stimulate the $\beta$-adrenoceptors, which could lead to mild or severe arrhythmias [71].

\section{Cardiogenic shock}

Hypotension may be also a sign of PHEO and may signify extensive myocardial involvement [87]. Patients with predominantly epinephrine-secreting tumors may present with hypotension and even shock in some severe cases [88]. Hypotension may also be secondary to sudden cessation of catecholamine secretion by PHEO removal in a patient with very low circulatory volume secondary to vasoconstriction and desensitized $\beta$-adrenoceptors [89]. PHEO should always be a consideration in patient who presents with severe hypotension especially if this was accompanied by abdominal pain, dyspnea secondary to pulmonary edema, pupil dilatation unresponsive to light stimulation, severe weakness, diaphoresis, cyanosis, hyperglycemia, and leukocytosis [14, 90-92]. 
Twenty percent of patients with PHEO may have hypotension, and $2 \%$ may present with cardiogenic shock [93]. Epinephrine- or dopamine-secreting PHEOs may present with hypotension since, specially epinephrine acts mainly on $\beta 2$-adrenoceptors situated on smooth muscles or peripheral arteries. On the other hand, norepinephrine-secreting PHEO manifests with hypertension due to $\alpha 1$-adrenoceptor mediated peripheral vasoconstriction [94, 95].

\section{Therapeutic Management of CICMPP}

The prompt recognition of the condition is important in the management of CICMPP [96-98]. Preoperative 2D echocardiogram should be strongly considered to all patients diagnosed with $\mathrm{PHEO}$, whether or not they present with signs and symptoms of heart failure because asymptomatic patients may have echocardiographic evidence of systolic or diastolic dysfunction.

Cardiac magnetic resonance has also emerged as an important diagnostic imaging in evaluation of metabolic cardiomyopathies such as caused by PHEOs. The study of Mavrogeni et al. discussed the role of CMR in the diagnosis, risk stratification and follow up of metabolic cardiomyopathies. CMR has the ability to accurately assess the anatomy, function, inflammation, rest stress myocardial perfusion, myocardial perfusion, aortic distensibility, iron and or fat deposition, thus can be utilized to for early detection of heart involvement, risk stratification, treatment evaluation and long term follow up of patient with metabolic cardiomyopathies including CICMPP [99]. Initial management is very important because it is related to a patient's prognosis [100]. Managing CICMPP is dependent on the type of its presentation [101], but clinicians should always consider specific treatment that will be initiated because some medical management that are usually given for specific condition may be absolutely contraindicated for PHEO [88]. Since it presents with various life threatening conditions such as heart failure, myocardial infarction, arrhythmias and shock, a definite PHEO diagnosis should be established immediately [101].

Once diagnosis of CICMPP is established, and patient is in acute decompensated heart failure, patient should be managed in the intensive care unit [97]. Management of CICMPP involves the stabilization of blood pressure by $\alpha$-adrenoceptor blockers followed by $\beta$-adrenoceptor blockers and surgical resection of PHEO once clinically stable [100]. Central to its therapeutic management is the use of $\alpha$-adrenoceptor blockade to inhibit their effects on $\alpha$-adrenoceptors and, therefore, many organ functions. To prevent unopposed $\alpha$-adrenergic action, $\beta$-adrenoceptor blockers are added to control tachycardia but only after appropriate $\alpha$-adrenoceptor blockade [88]. Target preoperative blood pressure is equal or less than $130 / 80 \mathrm{mmHg}$ while sitting and about $100 \mathrm{mmHg}$ while standing (but not less than $80 / 45 \mathrm{mmHg}$ ) and target heart rate of about 60-70 bpm when sitting, and 70-80 bpm when standing [102].

Blood pressure may not be easily controlled. Prolonged $\alpha$-adrenoceptor stimulation of increased levels of catecholamine could lead to intravascular volume contraction, and eventually hypotension. Thus, appropriate dosage of $\alpha$-adrenoceptor blockers is very important. Inadequate dosage could lead to hypertensive crisis and eventually hemodynamic instability [103]. In cases of acute decompensated CMP, intravenous boluses of phentolamine is preferred over phenoxybenzamine because it has rapid onset of action, so any adverse effects like hypotension would be short lasting. Once cardiovascular status is deemed to be stable after initiation of phentolamine bolus, phenoxybenzamine can be started with uptitration of dosage in the following days to achieve the target blood pressure [97]. Phentolamine could also be given as an intravenous infusion, especially for those with labile blood pressure. Once acute decompensation of CICMPP has resolved, an intravenous esmolol infusion could be started for heart rate and blood pressure control after adequate alpha blockade was given [103]. The Endocrine Society recommends a personalized approach in managing patients with PHEO. All patients with hormonally functional PHEO should be given $\alpha$-adrenoceptor blockade for at least 7 days prior to surgery [88].

Patients with CICMPP who present with acute heart failure should be given adequate diuretics to prevent respiratory failure. One of the setback in giving diuretics is when the case is complicated with hypotension, may it be secondary to intravascular volume contraction or systolic heart failure. A CVP line-guided monitoring of fluid status should be considered, in order to aid the clinician with adequate fluid resuscitation. Vasopressors such as norepinephrine, epinephrine, and dobutamine may be used, but may not be effective $[91,104,105]$. Mechanical circulatory support such as intra-arterial balloon counterpulsation or extracorporeal life support may be needed in cases of refractory hypotension $[98,106]$. Riester et al. did a systematic analysis of case reports of those patients who presented with life threatening complications such as CMP, myocardial infarction, pulmonary edema, cerebrovascular stroke, ischemic ileus, acute renal failure, and multiple organ failure. This study included 135 patients in three different referral centers in Germany in which 15 patients were admitted to the ICU due to life threatening complications. Among these 15 patients, three required a cardiac assist device in order for the cardiac output to improve. One of these three patients who had cardiac assist device had CMP, multiple organ failure (lung and kidneys), and eventually succumbed to death [51]. Hekimian et al. performed a prospective and systematic review on patients with PHEO-induced refractory cardiogenic shock treated with venoarterial-extracorporeal membrane oxygenation (VA-ECMO). The ejection fraction of all patients included was very severe (median LVEF $15 \%$ ). Of the 34 who were placed on VA-ECMO, all survived except for two patients [52].

ACE inhibitors or angiotensin receptor blockers are part of the pharmacologic therapy in patients with heart failure. One study, which used captopril, reported reversal of heart failure in a patient with PHEO and catecholamine-induced CMP. The signs and symptoms of heart failure improved within eight hours of administration of captopril and normalization of ejection fraction from $46 \%$ to $60 \%$ after two weeks treatment with captopril and alpha blockade was noted, however, this may be a class effect [107]. ACE inhibitors inhibit the growth and proliferation of myocytes and act as free radical scavengers, and improved signs of left-sided heart failure $[96,108]$. Until now, there is still no guideline recommending specific ACE inhibitor or ARB in the treatment of CICMPP.

Myocardial changes in CICMPP are improved in most cases after the administration of appropriate pharmacologic treatment and resection of PHEO. Time for improvement of heart changes due to CICMPP may take as short as 1-2 weeks or may be up to several 


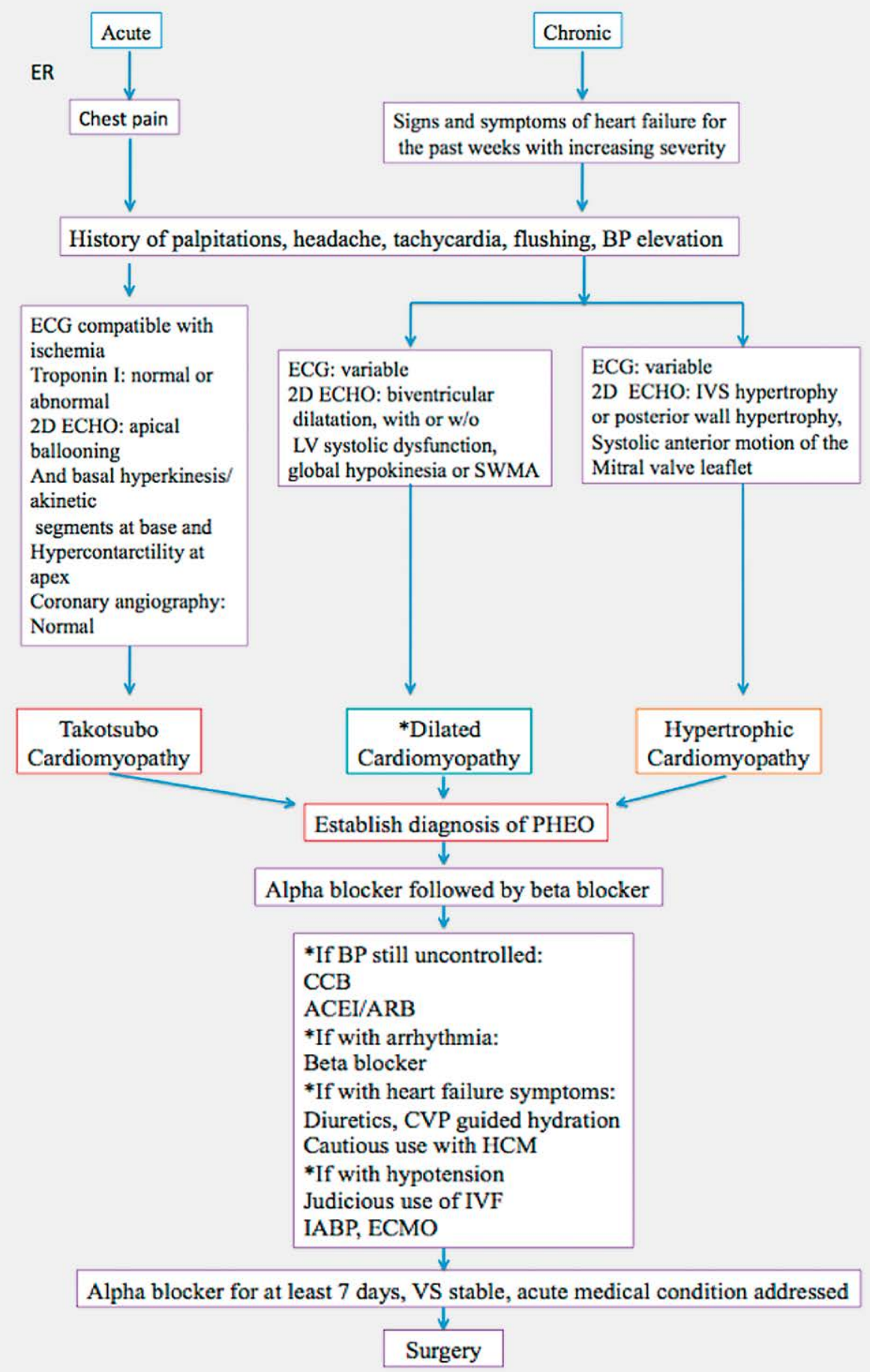

- Fig. 2 Approach to patient in management of CICP. * Dilated cardiomyopathy could also present acutely. SWMA: Segmental wall motion abnormality; CCB: Calcium channel blocker; ACEI: Angiotensin converting enzyme inhibitor; ARB: Angiotensin receptor blocker; CVP: Central venous pressure; HCM: Hypertrophic cardiomyopathy; IVF: Intravenous fluid; IABP: Intraarterial balloon pump; ECMO: Extracorporeal membrane oxygenation.

months [71]. - Fig. 2 shows the algorithm on the approach to patient in management of CICMPP. $>$ Table 2 shows the targeted diagnostic and therapeutic modalities for catecholamine-induced cardiomyopathy depending on clinical presentation.

\section{Conclusion}

Managing CICMPP is very complex. There are still no specific guidelines on managing this type of complication; however, there are some recommendations based on the general principles of managing patients who presented with hypertensive crisis, heart fail- 
- Table 2 Targeted diagnostic and therapeutic modalities for catecholamine-induced cardiomyopathy depending on clinical presentation.

\begin{tabular}{|c|c|c|c|}
\hline \multirow{2}{*}{ Clinical Presentation } & \multirow{2}{*}{ Diagnostic } & \multicolumn{2}{|c|}{ Therapeutic } \\
\hline & & Pharmacologic & Non Pharmacologic \\
\hline $\begin{array}{l}\text { Heart failure symptoms, } \\
\text { pulmonary congestion } \\
\text { (Dilated cardiomyopathy) }\end{array}$ & $\begin{array}{l}\text { Echocardiogram to assess for systolic and diastol- } \\
\text { ic dysfunction, and wall motion abnormalities } \\
\text { [56] }\end{array}$ & $\begin{array}{l}\text { Alpha blocker [88] } \\
\text { Beta blocker [88] } \\
\text { Calcium channel blocker [88] } \\
\text { ACEl } \\
\text { Diuretics [88] }\end{array}$ & Surgical resection [88] \\
\hline $\begin{array}{l}\text { Chest pain } \\
\text { (Takotsubo cardiomyo- } \\
\text { pathy) }\end{array}$ & $\begin{array}{l}\text { 1. ECG- typically ST elevation in acute phase, } \\
\text { followed by diffuse T wave inversion and QT } \\
\text { prolongation and subsequent resolution } \\
\text { 2. Cardiac biomarkers- minimally elevated } \\
\text { 3. Echocardiogram- assess for systolic and diastolic } \\
\text { dysfunction, and wall motion abnormalities } \\
\text { (Classic vs. Reversed Takotsubo cardiomyopathy) } \\
\text { 4. Coronary angiography- to rule out obstructive } \\
\text { coronary artery disease }\end{array}$ & $\begin{array}{l}\text { Alpha blocker } \\
\text { Beta blocker [88] }\end{array}$ & Surgical resection [88] \\
\hline $\begin{array}{l}\text { Left ventricular outflow } \\
\text { tract obstruction } \\
\text { (Hypertrophic } \\
\text { Cardiomyopathy) }\end{array}$ & $\begin{array}{l}\text { Echocardiogram- increased left ventricular mass } \\
\text { with or without systolic anterior motion and } \\
\text { increased left ventricular outflow gradient [61] }\end{array}$ & $\begin{array}{l}\text { Cautious diuretic use if } \\
\text { patient also present with } \\
\text { heart failure symptoms } \\
\text { Beta blockers }\end{array}$ & $\begin{array}{l}\text { Surgical resection- systolic anterior } \\
\text { motion and elevated left ventricular } \\
\text { outflow gradient will resolve after } \\
\text { resection }\end{array}$ \\
\hline Hypertension & Blood pressure monitoring & $\begin{array}{l}\text { Alpha blocker [88] } \\
\text { Beta blocker [88] } \\
\text { Calcium channel blocker [88] } \\
\text { ACEl [88] }\end{array}$ & Surgical resection [88] \\
\hline Hypotension & $\begin{array}{l}\text { Intra-arterial blood pressure monitoring } \\
\text { Central venous pressure monitoring }\end{array}$ & $\begin{array}{l}\text { Intravenous hydration } \\
{[88,97]} \\
\text { Alpha blocker [88] }\end{array}$ & $\begin{array}{l}\text { Vasopressors (norepinephrine, } \\
\text { epinephrine, dobutamine) } \\
\text { combined with mechanical } \\
\text { circulatory support [103] } \\
\text { Intra-aortic balloon counterpulsa- } \\
\text { tion }[98,104] \\
\text { Veno-arterial-extra corporeal } \\
\text { membrane oxygenation }[51,104] \\
\text { Left ventricular assist device [50] }\end{array}$ \\
\hline Arrhythmia & $\begin{array}{l}\text { ECG } \\
\text { Cardiac monitor } \\
\text { EPS to rule out accessory pathways }\end{array}$ & $\begin{array}{l}\text { Beta blocker [88] } \\
\text { Calcium channel blocker [88] } \\
\text { Antiarrhythmics }\end{array}$ & \\
\hline
\end{tabular}

ACEl: Angiotensin converting enzyme inhibitor; ECG: Electrocardiogram; EPS: Electrophysiology.

ure, and cardiogenic shock. Please note that when managing $\mathrm{CIC}$ MPP, one should take into consideration specific precautions in terms of intravenous fluid administration, type of antihypertensive medication that should be used, as well as heart failure medications, timing of surgery, and use of mechanical circulatory support.

The key to successful management of CICMPP is an urgent recognition of different clinical signs and symptoms pointing to this diagnosis and the detection of PHEO, requesting the appropriate diagnostic procedures, suitable administration of appropriate medical therapy, and definitive surgical therapy once clinical stabilization is achieved.

Follow up of these patients is also very important as part of its management so as to detect early recurrence of disease even if patients are asymptomatic to avoid life threatening complication due to sudden catecholamine release. Although in most cases of $\mathrm{CIC}$ MPP there is a recovery of systolic function with improvement of in terms of wall motion abnormalities and ejection fraction, there may be residual subclinical impairment as demonstrated by peak systolic strain rate and diastolic strain rate resulting in suboptimal long-term cardiac function [42].

\section{Funding}

U.S. Department of Health and Human Services, National Institutes of Health, Eunice Kennedy Shriver National Institute of Child Health and Human Development Grant No. Z1AHD008735.

\section{Conflict of Interest}

The authors declare that they have no conflict of interest. 
[1] Klein I. Endocrine Disorders and Cardiovascular Disease. Braunwald's Heart Disease a Textbook of Cardiovascular Medicine. 10th edition Mann DL, Zipes DP, Libby P, Bonow RO, Braunwald E. (eds) Philadelphia: Elsevier Saunders; 2015: 1793-1808

[2] Pacak K, Chrousos GP, Koch CA, Lenders JW, Eisenhofer G. Pheochromocytoma: Progress in diagnosis, therapy, and genetics. In: Margioris A, Chrousos GP. (eds) Adrenal Disorders. 1 ed. Vol 1:Totowa: Humana Press; 2001: 479-523

[3] Bajwa SS, Bajwa SK. Implications and considerations during pheochromocytoma resection: A challenge to the anesthesiologist. Indian J Endocrinol Metab 2011; 5: (Suppl 4): S337-S344

[4] Kantorovich V, Pacak K. Pheochromocytoma and paraganglioma. Prog Brain Res 2010; 182: 343-373

[5] Bravo EL. Evolving Concepts in the pathophysiology, diagnosis, and treatment of pheochromocytoma. Endocr Rev 1994; 15: 356-368

[6] Calhoun DA, Jones D, Textor S, Goff DC, Murphy TP, Toto RD, White A, Cushman WC, White W, Sica D, Ferdinand K, Giles TD, Falkner B, Carey RM. Resistant Hypertension: Diagnosis, evaluation, and treatment: A scientific statement from the American Heart Association Professional Education Committee of the Council for High Blood Pressure Research. Hypertension 2008; 51: 1403-1419

[7] Zuber SM, Kantorovich V, Pacak K. Hypertension in pheochromocytoma: Characteristics and treatment. Endocrinol Metab Clin North Am 2011; 40: 295-311

[8] Kalra Y, Agarwal H, Smith A. Perioperative management of pheochromocytoma and catecholamine-induced dilated cardiomyopathy in a pediatric patient. Pediatr Cardiol 2013; 34: 2013-3016

[9] Kobayashi Y, Kobayashi Y. Pheochromocytoma Found in Takotsubo Cardiomyopathy Patients. J Invasive Cardiol 2014; 26: E76-E77

[10] Yang YN, Chuang YC, Yin WH, Young MS. Catecholamine-Induced Cardiomyopathy Secondary to Pheochromocytoma Mimicking Fulminant Acute Myocarditis. Acta Cardiol Sin 2007; 23: 125-130

[11] Huddle KR, Kalliatakis B, Skoularigis J. Pheochromocytoma associated with clinical and echocardiographic features simulating hypertrophic obstructive cardiomyopathy. Chest 1996; 109: 1394-1397

[12] Park JH, Kim KS, Sul JY, Shin SK, Kim JH, Lee JH, Choi SW, Jeong J, Seong I. Prevalence and patterns of left ventricular dysfunction in patients with pheochromocytoma. J Cardiovasc Ultrasound 2011; 19: $76-82$

[13] Giavarini A, Chedid A, Bobrie G, Plouin P, Hagege A, Amar L. Acute catecholamine cardiomyopathy in patients with phaeochromocytoma or functional paraganglioma. Heart 2013; 99: 1438-1444

[14] Kassim TA, Clarke DD, Mai VQ, Clyde PW, Mohamed SA, Shakir KM. Catecholamine-induced cardiomyopathy. Endocr Pract 2008; 14: 1137-1149

[15] Eisenhofer G, Kopin IJ, Goldstein DS. Catecholamine metabolism: A contemporary view with implications for physiology and medicine. Pharmacol Rev 2004; 56: 331-349

[16] Schulz C, Eisenhofer G, Lehnert H. Principles of catecholamine biosynthesis, metabolism, and release. Front Horm Res 2004; 31 : $1-25$

[17] Gordan R, Gwathmey JK, Xie LH. Autonomic and endocrine control of cardiovascular function. World J Cardiol 2015; 7: 204-214

[18] Brodde OE, Michel MC. Adrenergic and Muscarinic Receptors in the Human Heart. Pharmacol Rev 1999; 51: 651-689

[19] Adameova A, Abdellatif Y, Dhalla NS. Role of the excessive amounts of circulating catecholamines and glucocorticoids in stress-induced heart disease. Can J Physiol Pharmacol 2009; 87: 493-514

[20] Klabunde RE. Neurohumoral Control of the Heart and Circulation. Cardiovascular Physiology Concepts. 2nd edition. Lippincott Williams and Wilkins; 2012: 117-139

[21] Rona G. Catecholamine Cardiotoxicity. J Mol Cell Cardiol 1985; 17 : 291-306

[22] Fleckenstein A, Janke J, Doring HJ, Pachinger O. Ca overload as determinant factor in the production of catecholamine induced myocardial lesion. In: Bajusz E, Rona G, Brink AJ, Lochner A. (ed) Recent Advances in Studies on Cardiac Structure and Metabolism. Vol 2: Baltimore, MD: University Park Press; 1973: 455-466

[23] Bloom S, Davis DL. Calcium as mediator of isoproterenol-induced myocardial necrosis. AM J Pathol 1972; 69: 459-470

[24] Fowler MB, Laser JA, Hopkins GL, Minobe WB, Bristow MR. Assessment of the $\beta$-adrenergic receptor pathway in the intact failing human heart: Progressive receptor down-regulation and subsensitivity to agonist response. Circulation 1986; 74: 1291-1301

[25] Koch W], Milano CA, Lefkowitz RJ. Transgenic manipulation of myocardial $G$ protein-coupled receptors and receptor Kinases. Circ Res 1986; 74: 1291-1301

[26] Pitcher JA, Freedman NJ, Lefkowitz RJ. G protein-coupled receptor kinases. Annu Rev Biochem 1998; 67: 653-692

[27] Chen Y, Best JA, Nagamoto K, Tan AW. Regulation of tyrosine hydroxylase gene expression by the $\mathrm{m} 1$ muscarinic acetycholine receptor in rat pheochromocytoma cells. Brain Res Mol Brain Res 1996; 40: 42-54

[28] Attar MN, Moulik PK, Salem GD, Rose EL, Khaleeli AA. Phaeochromocytoma presenting as dilated cardiomyopathy. Int J Clin Pract 2003; 57: 547-548

[29] Radtke WE, Kazmier F], Rutherford BD, Sheps SG. Cardiovascular complications of pheochromocytoma crisis. Am J Cardiol 1975; 35: 701-705

[30] Costa VM, Carvalho F, Bastos ML, Carvalho RA, Carvalho M, Remiao F. Contribution of catecholamine reactive intermediates and oxidative stress to the pathologic features of heart diseases. Curr Med Chem 2011; 18: 2272-2314

[31] Khan MU, Cheema Y, Shahbaz AU, Ahokas RA, Sun Y, Gerling IC, Bhattacharya SK, Weber KT. Mitochondria play a central role in nonischemic cardiomyocyte necrosis: Common to acute and chronic stressor states. Pflugers Arch 2012; 464: 123-131

[32] Amin JK, Xiao L, Pimental DR, Pagano PJ, Singh K, Sawyer DB, Colucci WS. Reactive oxygen species mediate $\alpha$-adrenergic receptor-stimulated hypertrophy in adult rat ventricular myocytes. J Mol Cell Cardiol 2001; 33: 131-139

[33] Behonick GS, Novak M], Nealley EW, Baskin SI. Toxicology update: the cardiotoxicity of the oxidative stress metabolites of catecholamines (aminochromes). J Appl Toxicol 2001; 21: (Suppl 1): S15-S22

[34] Bindoli A, Rigobello MP, Galzigna L. Toxicity of aminochromes. Toxicol Lett 1989; 48: 3-20

[35] Bindoli A, Deeble DJ, Rigobello MP, Galzigna L. Direct and respiratory chain-mediated redox cycling of adrenochrome. Biochim Biophys Acta 1990; 1016: 349-356

[36] Green DE, Richter D. Adrenaline and adrenochrome. Biochem J 1937; 31: 596-616

[37] Beamish RE, Dhillon KS, Singal PK, Dhalla NS. Protective effect of sulfinpyrazone against catecholamine metabolite adrenochrome-induced arrhythmias. Am Heart J 1981; 102: 149-152

[38] Yates JC, Beamish RE, Dhalla NS. Ventricular dysfunction and necrosis produced by adrenochrome metabolite of epinephrine: Relation to pathogenesis of catecholamine cardiomyopathy. Am Heart J 1981; 102: $210-221$

[39] Taam GM, Takeo S, Ziegelhoffer A, Singal PK, Beamish RE, Dhalla NS. Effect of adrenochrome on adenine nucleotides and mitochondrial oxidative phosphorylation in rat heart. Can J Cardiol 1986; 2: 88-93 
[40] Zhang R, Gupta D, Albert SG. Pheochromocytoma as a reversible cause of Cardiomyopathy: Analysis and review of the literature. Int J Cardiol 2017; 249: 319-323

[41] Sanchez MA, Esteban MR, Pineda SO, Ortiz MR, Peña ER, Rubio DM, Belsue FV. Clinical outcome and reversibility of systolic dysfunction in patients with dilated cardiomyopathy due to hypertension and chronic heart failure. Rev Esp Cardiol 2004; 57: 834-841

[42] Ferreira VM, Marcelino M, Piechnik SK, Marini C, Karamitsos TD, Ntusi NAB, Francis JM, Robson MD, Arnold JR, Thomas JDJ, Herincs M, Hassan-Smith ZK, Greiser A, Wiebke A, Korbonits M, Karavitaki N, Grossman AB, Wass JAH, Neubauer S. Pheochromocytoma Is Characterized by Catecholamine-Mediated Myocarditis, Focal and Diffuse Myocardial Fibrosis, and Myocardial Dysfunction. JACC 2016; 67: 2364-2374

[43] Lyon AR, Rees PS, Prasad S, Poole-Wilson PA, Harding SE. Stress (Takotsubo) cardiomyopathy - a novel pathophysiological hypothesis to explain catecholamine-induced acute myocardial stunning. Nat Clin Pract Cardiovasc Med 2008; 5: 22-29

[44] Batisse-Lignier M, Pereira B, Motreff P, Pierrard R, Burnot C, Magdasy S, Roche B, Desbiez F, Clerfond G, Citron B, Lusson JR, Tauveron I, Eschaller R. Acute and Chronic Pheochromocytoma-Induced Cardiomyopathies: Different Prognoses? : A Systematic Analytic Review. Medicine (Baltimore) 2015; 94: e298

[45] Schurmeyer TH, Engeroff B, Dralle H, Muhlen VZ. Cardiological Effect of Catecholamine-Secreting Tumours. Eur J Clin Invest 1997; 27: 189-195

[46] Sadowski D, Cujec B, McMeekin JD, Wilson TW. Reversibility of catecholamine-induced cardiomyopathy in a woman with pheochromocytoma. CMAJ 1989; 141: 923-924

[47] de Miguel V, Arias A, Paissan A, de Arenaza DP, Pietrani M, Jurado A, Jaen A, Fainstein Day P. Catecholamine-induced myocarditis in pheochromocytoma. Circulation 2014; 129: 1348-1349

[48] Matias-Guiu JA, Ramos-Levi A, Sanabria-Perez C. Catecholamine-induced cardiomyopathy triggered by pheochromocytoma. Endocrinol Nutr 2011; 58: 204-206

[49] Brilakis ES, Young WF Jr, Wilson JW, Thompson GB, Munger TM. Reversible catecholamine-induced cardiomyopathy in a heart transplant candidate without persistent or paroxysmal hypertension. J Heart Lung Transplant 1999; 18: 376-380

[50] Riester A, Weismann D, Quinkler M, Lichtenauer UD, Sommerrey S, Halbritter R, Penning R, Spitzweg C, Schopohl J, Beuschlein F, Reincke M. Life-threatening events in patients with pheochromocytoma. Eur J Endocrinol 2015; 173: 757-764

[51] Hekimian G, Kharcha F, Brechot N, Schmidt M, Ghander C, Lebreton G, Girerd X, Tresallet C, Trouillet JL, Leprinc P, Chastre J, Combes A, Luyt CE. Extracorporeal membrane oxygenation for pheochromocytoma-induced cardiogenic shock. Ann Intens Care 2016; 6: 117

[52] Tagawa M, Nanba H, Suzuki H, Nakamura Y, Uchiyama H, Ochiai S, Terunuma M, Yahata K, Minamino T. Ventricular Rhythm and Hypotension in a Patient with Pheochromocytoma-induced Myocardial Damage and Reverse Takotsubo Cardiomyopathy. Intern Med 2015; 54: 2343-2349

[53] Naderi N, Amin A, Setayesh A, Pouraliakbar H, Mozaffari K, Maleki M. Pheochromocytoma-induced reverse tako-tsubo with rapid recovery of left ventricular function. Cardiol J 2012; 19: 527-531

[54] Long SL, Whitlock RP, Schwalm JDR. Pheochromocytoma-induced reverse Takotsubo cardiomyopathy leading to fulminant pulmonary edema: Successful intervention with an impella $\mathrm{CP} \circledast$ percutaneous ventricular assist device. J Cardiol Clin Res 2016; 4: 1068

[55] Kim TS, Chu EH, Kang HH, Chun SW, Cho EJ, Kim JH. A case of reversal of Takotsubo cardiomyopathy in patient with pheochromocytoma. J Cardiovasc Ultrasound 2007; 15: 50-54
[56] Falk RH, Hershberger RE. The Dilated, Restrictive, and Infiltrative Cardiomyopathies. Braunwald's Heart Disease a Textbook of Cardiovascular Medicine. 10th edition Mann DL, Zipes DP, Libby P, Bonow RO, Braunwald E. (eds)Philadelphia: Elsevier Saunders; 2015: 1551-1573

[57] Wittstein IS, Thiemann DR, liama JA, Baughman KL, Schulman SP, Gerstenblith G, Wu KC, Rade JJ, Bivalacqua TJ, Hunter CC. Neurohumural features of myocardial stunning due to sudden emotional stress. N Engl J Med 2005; 352: 539-548

[58] Agarwal V, Kant G, Hans N, Messerl FH. Takotsubo-like cardiomyopathy in pheochromocytoma. Int J Cardiol 2001; 153: 241-248

[59] Di Valentino M, Balestra GM, Christ M, Raineri I, Oertli D, Zellweger MJ. Inverted Takotsubo cardiomyopathy due to pheochromocytoma. Eur Heart J 2008; 29: 830

[60] Sanchez-Recalde A, Costero O, Oliver JM, Iborra C, Ruiz E, Sobrino JA. Images in cardiovascular medicine. Pheochromocytoma-related cardiomyopathy: Inverted Takotsubo contractile pattern. Circulation 2006; 113: e738-e739

[61] Maron B], Olivotto I. Hypertrophic cardiomyopathy. Braunwald's Heart Disease a Textbook of Cardiovascular Medicine 10th edition. Mann DL, Zipes DP, Libby P, Bonow RO, Braunwald E. (eds) Philadelphia: Elsevier Saunders; 2015: 1574-1588

[62] Jacob JL, da Silveira LC, de Freitas CG, Centola CA, Nicolau JC, Lorga AM. Pheochromocytoma with echocardiographic features of obstructive hypertrophic Cardiomyopathy. A case report. Angiology 1994; 45: 958-959

[63] Golbasi Z, Sakalli M, Cicek D, Aydogdu S. Dynamic left ventricular outflow tract obstruction in a patient with pheochromocytoma. Jpn Heart J 1999; 40: 831-835

[64] Jozwik-Plebanek K, Klisiewicz A, Januszewicz A, Prejbisz A. Transient dynamic left ventricular outflow tract obstruction in a Patient with pheochromocytoma. Kardiol Pol 2014; 72: 472

[65] Jayaprasad N, Madhavan S. Pheochromocytoma presenting as acute myocardial infarction. Nepal Heart J 2015; 12: 89-92

[66] Jang SY, Yang DH, Lee SH, Kim JH, Park SH, Park HS, Cho Y, Chae S, Jun JE, Park WH. Recurrent catecholamine-induced cardiomyopathy in a patient with a pheochromocytoma. Korean Circ J 2009; 39: 254-257

[67] Suh IW, Lee CW, Kim YH, Hong MK, Lee JW, Kim J], Park SW, Park S]. Catastrophic catecholamine-induced cardiomyopathy mimicking acute myocardial infarction, rescued by extracorporeal mebrane oxygenation (ECMO) in pheochromocytoma. J Korean Med Sci 2008; 23: $350-354$

[68] De Backer TL, De Buyzere ML, Taeymans Y, Kunnen P, Rubens R, Clement DL. Cardiac involvement in pheochromocytoma. J Hum Hypertens 2000; 14: 469-471

[69] Sanna GD, Talanas G, Fiore G, Canu A, Terrosu P. Pheochromocytoma presenting as an acute coronary syndrome complicated by acute heart failure: The challenge of great mimic. J Saudi Heart Assoc 2016; 28: $278-282$

[70] Scanlon PJ, Faxon DP, Audet AM, Carabello B, Dehmer G], Eagle KA, Legako RD, Leon DF, Murray JA, Nisse SE, Pepine CJ, Watson RM, Ritche JL, Gibbons RJ, Cheitlin MD, Garson A Jr., Russell RO Jr., Ryan TJ, Smith SC Jr.. ACC/AHA guidelines for coronary angiography. J Am Coll Cardiol 1999; 33: 1756-1824

[71] Prejbisz A, Lenders JW, Eisenhofer G, Januszewicz A. Cardiovascular manifestations of phaeochromocytoma. J Hypertens 2011; 29: 2049-2060

[72] van Iperen CE, Giezen J, Kramer WL, Lips C], Bartelink AK. Acute dyspnea resulting from pulmonary oedema as the first sign of a phaeochromocytoma. Respiration 2001; 68: 323-326

[73] Nepal S, Giri S, Bhusal M, Siwakoti K, Pathak R. An uncommon cause of acute pulmonary edema. JAAPA 2016; 29: 1-4 
[74] Takeshita T, Shima H, Oishi S, Machida N, Uchiyama K. Noncardiogenic pulmonary edema as the first manifestation of pheochromocytoma: case report. Radiat Med 2005; 23: 133-138

[75] Malek LA, Werys K, Klopotowski M, Spiewak M, Milosz-Wleczorek B, Mazurkiewicz L, Petryka-Mazurkiewicz J, Marczak M, Witkowski A. Native T1-mapping for non-contrast assessment of myocardial fibrosis in patients with hypertrophic cardiomyopathy-comparison with late enhancement quantification. Magn Reson Imaging 2015; 33: 718-724

[76] Puntmann VO, Voigt T, Chen Z, Mayr M, Karim R, Rhode K, Pastor A, Carr-White G, Razavi R, Schaeffter T, Nagel E. Native T1 mapping in differentiation of normal myocardium from diffuse disease in hypertrophic and dilated cardiomyopathy. JACC Cardiovasc Imaging 2013; 6: 475-484

[77] Lenders JW, Eisenhofer G, Manneli M, Pacak K. Pheochromocytoma. Lancet 2005; 366: 665-675

[78] Li S], Wang T, Wang L, Pang ZQ, Ma B, Li YW, Yang J, Dong H. Ventricular Tachycardia and Resembling Acute Coronary Syndrome During Pheochromocytoma Crisis. A case Report. Medicine (Baltimore) 2016; 95: e3297

[79] Kokkonen JO, Lammintausta O, Luomanmaki K. Acute heart failure and transient low voltage in electrocardiogram after massive catecholamine release from a phaeochromocytoma. Eur Heart J 1997; 18: 1357

[80] Choi SY, Cho KI, Han YJ, You GI, Kim JH, Heo JH, Kim HS, Cha TJ, Lee JW. Impact of Pheochromocytoma on Left Ventricular Hypertrophy and QTc Prolongation: Comparison with Takotsubo Cardiomyopathy. Koren Circ J 2014; 44: 89-96

[81] Cheng TO, Bashour TT. Striking electrocardiographic changes associated with pheochromocytoma. Masquerading as ischemic heart disease. Chest 1976; 70: 397-399

[82] Zweiker R, Tiemann M, Eber B, Schumacher M, Fruhwald FM, Lipp R, Lax S, Pristautz H, Klein W. Bradydysrhythmia-related presyncope secondary to pheochromocytoma. J Intern Med 1997; 242: 249-253

[83] Shimizu K, Miura Y, Meguro Y, Noshiro T, Ohzeki T, Kusakari T, Akama H, Watanabe T, Honma H, Imai Y, Yoshinaga K, Totsuka H. QT prolongation with torsades de pointes in pheochromocytoma. Am Heart J 1992; 124: 235-239

[84] Hajdusek P, Pazdernik M, Kettner ], Kautzner J. Pheochromocytoma as a rare cause of ventricular fibrillation. Interv Akut Kardiol 2016; 15: 187-190

[85] Delekta J, Riahi S, Eschen O. Rare cause of ventricular tachycardia: Pheochromocytoma. J Cardiol Cases 2015; 11: 62-65

[86] Methe H, Hinterseer M, Wilbert-Lampen U, Beckmann BM, Steinbeck G, Kaab S. Torsades de Pointes: A rare complication of an extra-adrenal pheochromocytoma. Hyperten Res 2007; 30: 1263-1266

[87] Shaw TR, Rafferty P, Tait GW. Transient Shock and myocardial impairment caused by phaeochromocytoma crisis. Br Heart J 1987; 57: 194-198

[88] Lenders JW, Duh QY, Eisenhofer G, Gimenez-Roqueplo AP, Grebe SK, Murad MH, Naruse M, Pacak K, Young WF Jr. Endocrine Society. Pheochromocytoma and paraganglioma: An endocrine society clinical practice guideline. J Clin Endocrinol Metab 2014; 99 : 1915-1942

[89] Olson SW, Deal LE, Piesman M. Epinephrine-secreting pheochromocytoma presenting with cardiogenic shock and profound hypocalcemia. An Intern Med 2004; 140: 849-851

[90] Brukamp K, Goral S, Townsend RR, Silvestry FE, Torigian DA. Rapidly reversible cardiogenic shock as a pheochromocytoma presentation. Am J Med 2007; 120: e1-e2
[91] Grasselli G, Foti G, Patroniti N, Rona R, Perlangeli MV, Pesenti A. Extracorporeal cardiopulmonary support for cardiogenic shock caused by pheochromocytoma: A case report and literature review. Anesthesiology 2008; 108: 959-962

[92] Kizer JR, Koniaris LS, Edelman JD, St John Suton MG. Pheochromocytoma crisis, cardiomyopathy, and hemodynamic collapse. Chest 2000; 118: 1221-1223

[93] Bergland BE. Pheochromocytoma presenting as shock. Am J Emerg Med 1989; 7: 44-48

[94] Chatzizisis YS, Ziakas A, Feloukidis C, Paramythiotis D, Hadjimiltiades S, Iliadis A, Basdanis G, Styliadis I. Pheochromocytoma crisis presenting with cardiogenic shock. Herz 2014; 39: 156-160

[95] Benowitz NL. Pheochromocytoma-recent advances in diagnosis and treatment. West J Med 1988; 148: 561-567

[96] Satendra M, de Jesus C, Bordalo e Sa AL, Rosario L, Rocha J, Bicha Castelo H, Correia MJ, Nunes Diogo A. Reversible catecholamine-induced cardiomyopathy due to pheochromocytoma. Rev Port Cardiol 2014; 33: 177.e1-177.e6

[97] Casey RT, Challis BG, Pitfield D, Mahroof RM, Jamieson N, Bhagra C], Vulysteke A, Pettit SJ, Chatterjee KC. Management of an acute catecholamine-induced cardiomyopathy and circulatory collapse: A multidisciplinary approach. Endocrinol Diabtes Metab Case Rep 2017; pii: 17-0122 doi:10.1530/EDM- 17-0122 eCollection 2017 1-6

[98] Steppan J, Shields J, Lebron R. Pheochromocytoma presenting as acute heart failure leading to cardiogenic shock and multiorgan failure. Case Rep Med 2011; 2011: 596354

[99] Mavrogeni S, Markousis-Mavrogenis G, Markussis V, Kolovou G. The Emerging Role of Cardiovascular Magnetic Resonance Imaging in the Evaluation of Metabolic Cardiomyopathies. Horm Metab Res 2015; 47: 623-632

[100] Jessurun CR, Adam K, Moise KJ Jr., Wilansky S. Pheochromocytoma-induced myocardial infarction in pregnancy. A case report and literature review. Tex Heart Inst J 1993; 20: 120-122

[101] Scholten A, Cisco RM, Vriens MR, Cohen JK, Mitmaker E], Liu C, Tyrrell JB, Shen WT, Duh QY. Pheochromocytoma Crisis is not a Surgical Emergency. J Clin Endocrinol Metab 2013; 98: 581-591

[102] Pacak K. Preoperative management of the pheochromocytoma patient. J of Clin Endocrinol Metab 2007; 92: 4069-4079

[103] McMillian WD, Trombley B], Charash WE, Christian RC. Phentolamine continuous infusion in a patient with pheochromocytoma. Am J Health Syst Pharm 2011; 6: 130-134

[104] Taliercio J], Bravo E. An unusual presentation of pheochromocytoma. NDT Plus 2011; 4: 331-334

[105] Ritter S, Guertler T, Meier CA, Genoni M. Cardiogenic shock due to pheochromocytoma rescued by extracorporeal membrane oxygenation. Interact Cardiovasc Thorac Surg 2011; 13: 112-113

[106] Whitelaw BC, Prague JK, Mustafa OG, Schulte KM, Hopkins PA, Gilbert JA, McGregor AM, Aylwin SJ. Phaeochromocytoma [corrected] crisis. Clin Endocrinol (Oxf) 2014; 80: 13-22

[107] Salathe M, Weiss O, Ritz R. Rapid reversal of heart failure in a patient with phaeochromocytoma and catecholamine-induced cardiomyopathy who was treated with captopril. Br Heart J 1992; 68: 527-528

[108] Dzau VJ. Cardiac Renin-Angiotensin System: Molecular and Functional Aspects. AM J Med 1988; 84: 22-27 